\title{
Expedient Single Step Access to Strained Tricyclic Ketals
}

Sravan K. Jonnalagadda ${ }^{1}$, Bader I. Huwaimel ${ }^{1,2}$, Shirisha Jonnalagadda ${ }^{1}$, Jered C.Garrison ${ }^{1,3}$ and Paul C. Trippier ${ }^{1,3,4, *}$

1Department of Pharmaceutical Sciences, College of Pharmacy, University of Nebraska Medical Center, Omaha, NE 68106, USA.

${ }^{2}$ Department of Pharmaceutical Chemistry, College of Pharmacy, University of Hail, Hail, Kingdom of Saudi Arabia.

${ }^{3}$ Fred \& Pamela Buffett Cancer Center, University of Nebraska Medical Center, Omaha, NE 68106, USA.

${ }^{4}$ UNMC Center for Drug Discovery, University of Nebraska Medical Center, Omaha, NE 68106, USA. "Corresponding Author Email Address: paul.trippier@unmc.edu 


\section{Abstract}

The synthesis of cyclopropyl methyl ketones and highly strained fused substituted dihydrobenzopyran cyclopropyl lactones derived from coumarin carboxylates and chloroacetone in the presence of potassium carbonate is reported. One step synthetic access to the previously unknown dihydrobenzopyran cyclopropyl tricyclic ketals is achieved with wide substrate scope. Substituted coumarin carboxylates, phenylamides or a quinolin-2(1H)-one possessing alkyl electron donating (methyl, t-butyl) and electron withdrawing groups $\left(\mathrm{F}, \mathrm{Cl}, \mathrm{Br}, \mathrm{NO}_{2}\right)$ in the 4 or 6 positions formed the highly strained dihydrobenzopyran cyclopropyl tricyclic ketals in moderate yield alongside the expected coumarin carboxylate. Saturation or substitution at the 5-position or 6-OMe afforded no tricyclic ketal compound but solely coumarin carboxylates. The formation of both structures in selected derivatives was confirmed by X-ray crystallography. A plausible mechanism is proposed for the formation of the fused lactone; via intramolecular rearrangement of cis cyclopropyl methyl ketones with phenolic acetate via the formation of a hemiacetal. 
The search for novel chemical space in pharmaceutical discovery has correlated increasing three-dimensional space with an increased propensity to identify a clinical candidate. Thus, $\mathrm{sp}^{3}$ rich scaffolds have garnered increased attention from the medicinal chemistry community, leading to a new predictive metric $\mathrm{Fsp}^{3}$; the fraction of $\mathrm{sp}^{3}$ carbon atoms within a compound. ${ }^{1-3}$ Of specific interest has been the introduction of multi-cyclic, fused, bridged, or spiro-fused rings. ${ }^{4-6}$

The cyclopropane ring is a constituent of many compounds that have biological activity, including numerous natural products and pharmaceuticals used in the clinical management of cardiovascular, inflammatory diseases, diabetes and cancer. $^{7}$ Furthermore, coumarin derivatives have been extensively studied due to their wide-ranging biological profiles, including activity as anticancer, antiinflammatory, antibacterial, antifungal, and anticoagulant agents. ${ }^{8}$ Despite the potential for increased biological activity, cyclopropanated derivatives of coumarins have not been extensively investigated.

In the course of our continued efforts to identify new aldo-keto reductase 1C3 (AKR1C3) inhibitors, we desired access to cyclopropyl-fused coumarins. ${ }^{9-13}$ Thus, we investigated the utility of a Michael initiated ring closure (MIRC) reaction. Prior precedent demonstrates cyclopropanation can be achieved at $\alpha, \beta$-unsaturated alkenes, such as those present in the coumarin structure, with activated methylene substrates via the MIRC reaction, ${ }^{14}, 15$ which includes the use of 1,2-dicarboxylate substituted alkenes ${ }^{16}$ and 1,1,2-trisubstituted alkenes, ${ }^{17}$ among others. ${ }^{18}$ However, reaction with highly activated halomethylene ketones has been understudied due to high reactivity and potential for selfpolymerization. ${ }^{19}$

While this work was in progress, Sun et. al. reported the reaction of a coumarin carboxylate with tert-butyl 2-bromoacetate using a chiral Lewis base catalyst and $\mathrm{Cs}_{2} \mathrm{CO}_{3}$ which provided polycyclic ketones in predominantly high yields (Figure 1). ${ }^{20}$ However, when the reaction was performed without either base at room temperature, either there was no reaction, or in the case of carbonyl coumarins, a set of complex products prevented the purification of the desired cyclopropanation derivative. Guo et. al. reported an enatioselective cyclopropanation reaction employing a phenyliodonium ylide that was tolerative of unsubstituted or 6-methyl substituted coumarins. ${ }^{21}$ The synthesis of functionalized strained 
bicylic ketals, where $\mathrm{n}=1$ or 2 (Figure 1), from bis-homopropargylic diols via use of a Au' or Au ${ }^{\text {III }}$ catalyst was reported by Antoniotti et. al. ${ }^{22}$
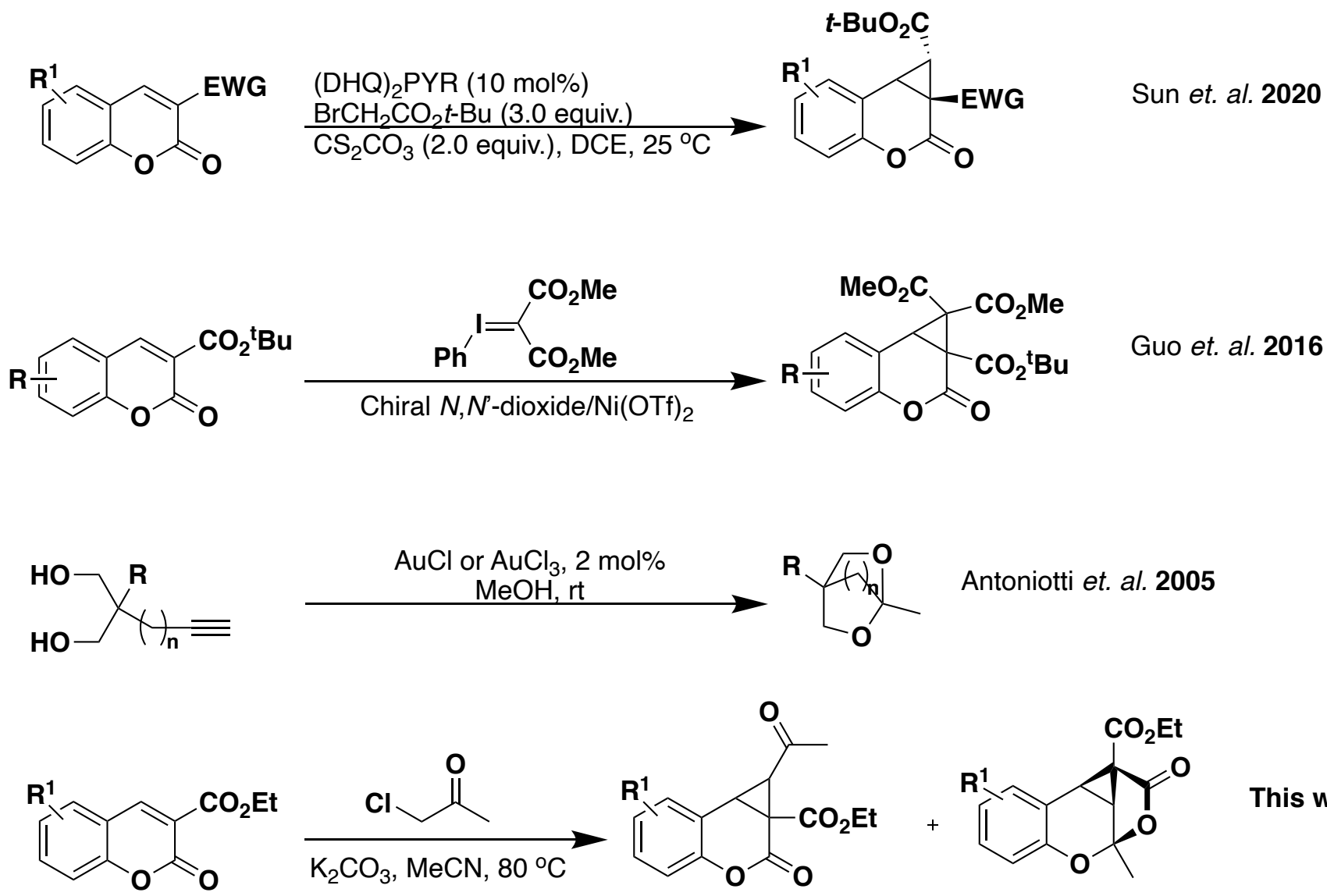

This work

Figure 1. Comparison of the reported work and that of cyclopropanation of coumarins (Sun et. al. and Guo et. al.) and the formation of strained bicyclic ketals (Antoniotti et. al.).

The reaction of coumarin carboxylates with bromoacetophenones leads to the formation of cyclopropanated benzophenone and/or benzofuran derivatives. ${ }^{23,}{ }^{24}$ During the course of our synthetic efforts to access cyclopropanated coumarins we intriguingly isolated and characterized a unique tricyclic ketal that, to the best of our knowledge, has not previously been disclosed.

Reaction yields were found to be highly dependent on the substituents of the coumarin starting material. To this end, we first exposed 5-hydroxy coumarin ethyl ester (1) to base and stoichiometric amounts of chloroacetone. Total consumption of the starting material was not observed and so addition of excess chloroacetone and $\mathrm{K}_{2} \mathrm{CO}_{3}$ was attempted. These conditions led to the formation of the 
cyclopropanated methyl ketone derivative (1a) complete with reaction of the chloroacetone with the alcohol to afford the respective ether (Scheme 1).

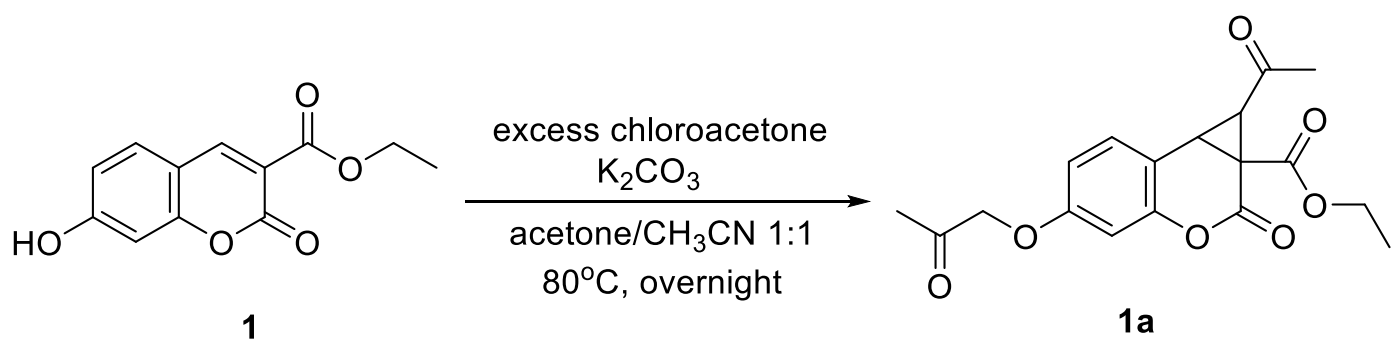

Scheme 1: Cyclopropanation of hydroxy coumarin carboxylic acid ethyl ester

We next switched to an unsubstituted coumarin ethyl ester as starting material which resulted in the formation of a complex mixture of products with the desired fused cyclopropyl product in trace yield. Optimization of reaction conditions using the 6-bromocoumarin ethyl ester (9a) began with a base scan (Table 1). However, no to low yields of product were formed with the use of $\mathrm{Na}_{2} \mathrm{CO}_{3}, \mathrm{CaCO}_{3}, \mathrm{NaOMe}$, $\mathrm{NaOEt}, \mathrm{KOEt}, \mathrm{NaHCO}_{3}$, or $\mathrm{KHCO}_{3}$. Furthermore, no significant improvement in yield was observed with additives including a 2:1 ratio of $\mathrm{Na}_{2} \mathrm{CO}_{3}+\mathrm{DABCO}, \mathrm{Na}_{2} \mathrm{CO}_{3}+\mathrm{Et}_{3} \mathrm{~N}$, or $\mathrm{Na}_{2} \mathrm{CO}_{3}+\mathrm{K}_{2} \mathrm{CO}_{3}$. In all cases, final products were isolated via silica gel column chromatography and recrystallized in $20 \%$ EtOAc:Hexanes. These purification conditions identified the unusual highly strained tricyclic ketal $\mathbf{9 b}$ as the major product alongside fused cyclopropyl coumarin $9 a$. The structures of $9 a$ and $9 b$ were confirmed by ${ }^{1} \mathrm{H}$ and ${ }^{13} \mathrm{C}$ spectroscopy. Representative examples for the structures of type $\mathbf{a}$ and $\mathbf{b}$, and cis and trans isomers of a were confirmed by 2D NMR and X-ray crystallography. 
Table 1: Reaction condition optimization for cyclopropanation<smiles></smiles>

\begin{tabular}{|l|c|l|}
\hline Entry & Base & Combined yield \\
\hline 1 & $\mathrm{Na}_{2} \mathrm{CO}_{3}$ & no product/trace \\
\hline 2 & $\mathrm{CaCO}_{3}$ & no product/trace \\
\hline 3 & $\mathrm{~K}_{2} \mathrm{CO}_{3}$ & $40 \%$ \\
\hline 4 & $\mathrm{Cs}_{2} \mathrm{CO}_{3}$ & $38 \%$ \\
\hline 5 & $\mathrm{Na}_{2} \mathrm{CO}_{3}+\mathrm{DABCO}(2: 1)$ & $40 \%$ \\
\hline 6 & $\mathrm{Na}_{2} \mathrm{CO}_{3}+\mathrm{Et}_{3} \mathrm{~N}(2: 1)$ & $35 \%$ (difficulty in isolation) \\
\hline 7 & $\mathrm{Na}_{2} \mathrm{CO}_{3}+\mathrm{K}_{2} \mathrm{CO}_{3}(2: 1)$ & $40 \%$ \\
\hline 8 & $\mathrm{NaHCO}_{3}$ & no product/trace \\
\hline 9 & $\mathrm{KHCO}_{3}$ & no product/trace \\
\hline 10 & $\mathrm{NaOMe}$ & no product/race \\
\hline 11 & $\mathrm{NaOEt}$ & no product/trace \\
\hline 12 & $\mathrm{KOEt}$ & no product/trace \\
\hline 13 & $\mathrm{KO} B \mathrm{Bu}$ & $15 \%$ (difficulty in isolation) \\
\hline 14 & $\mathrm{Et} \mathrm{H}_{3} \mathrm{n}$ & no product/trace \\
\hline 15 & Aqueous $\mathrm{K}_{2} \mathrm{CO}_{3}$ & Polymerized products \\
\hline
\end{tabular}

We utilized $\mathrm{K}_{2} \mathrm{CO}_{3}$ as the base for further synthesis of substituted derivatives due to the ease of purification and isolation of products. Synthesis of a library of derivatives from substituted coumarins including electron donating groups; 6-methyl (3), 4-methoxy (4), 6-methoxy (5), 4-tert-butyl (6), and electron withdrawing groups; 5-OH (1), 6-fluoro (7), 6-chloro (8), 6-bromo (9), 4,6-dibromo (10), 6-nitro (11) and O-benzyl (14) were utilized. These substrates resulted in consistent formation of the fused cyclopropyl coumarin and the tricyclic ketal in low to moderate, but still synthetically useful yields in all case with starting material bearing 4-, 6- or 4,6-substitution. To further probe the substrate scope coumarin benzamide (12), quinolin-2(1H)-one (13) and 4-diethylamine (15) were also investigated (Figure 2).

5-Hydroxy, saturated, and 5-OBn coumarins (1, 2 and 14 respectively) resulted in isolation of the cyclopropylated coumarin (overall $31 \%, 35 \%$ and $31 \%$ yield) as the major product with only trace tricyclic product detected. The 6-methyl (3), 6-fluoro (7), 6-chloro (8) and benzamide (12) coumarin 
substrates all provided preference to the tricyclic ketal as the sole isolated product $(22 \%, 40 \%, 13 \%$ and $31 \%$ yield respectively). It should be noted that when the 6 -fluoro coumarin cyclopropylated product was purified by silica gel chromatography without a methanol wash, decomposition of the product was observed. However, washing the product with methanol followed by silica gel chromatography resulted in trans isomerization of ethyl ester to methyl ester $\mathbf{7 b}$. Similar results was observed with 4-tert butyl isomerized methyl ester $\mathbf{6 b}$. Interestingly switching an unsubstituted coumarin ethyl ester to the respective unsubstituted benzamide (12) resulted in switch of major product from the cyclopropylated coumarin to the tricyclic ketal (Figure 2).

The 4-methoxy (4), 6-bromo (9) and 4,6-dibromo (10) substituted coumarin substrates provided an approximate 1:1 ratio of fused cyclopropyl coumarin and the tricyclic ketal. Lower equivalents of chloroacetone did not lead to the consumption of starting material in the case of 5-hydroxy and 6-nitro coumarins, hence, excess chloroacetone (5 equiv.) was used for these reactions. Difficulty in purification was observed if the starting material was not consumed. Use of excess chloroacetone (5 equiv.) with 6-nitro coumarin 11 lead to the formation of tricyclic ketal 11b and a ring-opened alkylated diester 11c (supporting information).

Interestingly, 6-methoxy substituted starting material (5) afforded the cyclopropyl coumarin as the major and only product in a 1:1 mixture of cis and trans isomers as confirmed by X-ray crystallography (Figure 3C/D). Substrate scope was further extended with quinolin-2(1H)-one (13) which afforded a mixture of the respective $N$-alkylated compound and the cyclopropyl coumarin (13a) in equivalent yield but with no tricyclic ketal isolated.

Cyclopropanation of 5-diethylamine coumarin 15 yielded no isolated product under the conditions depicted in Figure 2. However, when the conditions were modified to KO'Bu in THF at -78 ${ }^{\circ} \mathrm{C}$ the cyclopropyl coumarin was isolated in poor yield with no evidence of ketal formation (Scheme 2), again suggesting that substitution at the 5 -position is unfavorable for tricyclic ketal formation. 
<smiles>CCOC(=O)c1cc2ccc(N(CC)CC)cc2oc1=O</smiles>

15<smiles>CCOC(=O)C12C(=O)Oc3cc(N(CC)CC)ccc3C1C2C(C)=O</smiles>

$15 a, 5 \%$

Scheme 2: Cyclopropanation of $\mathrm{N}, \mathrm{N}$-diethyl coumarin carboxylic acid ethyl ester.

Table 2: Substrate scope and isolate product yields

\begin{tabular}{|c|c|c|}
\hline Substrate & $\begin{array}{c}\text { Equiv. } \\
\text { Chloroacetone }\end{array}$ & Products isolated and yields \\
\hline & 5 & $1 \mathrm{a}, 35 \%$ \\
\hline & 2 & $2 a, 31 \%$ \\
\hline 3 & 2 & $3 \mathbf{b}, 22 \%$ \\
\hline 4 & 2 & $4 a, 5 \%$ \\
\hline 5 & 2 & $5 a, 44 \%$ \\
\hline
\end{tabular}




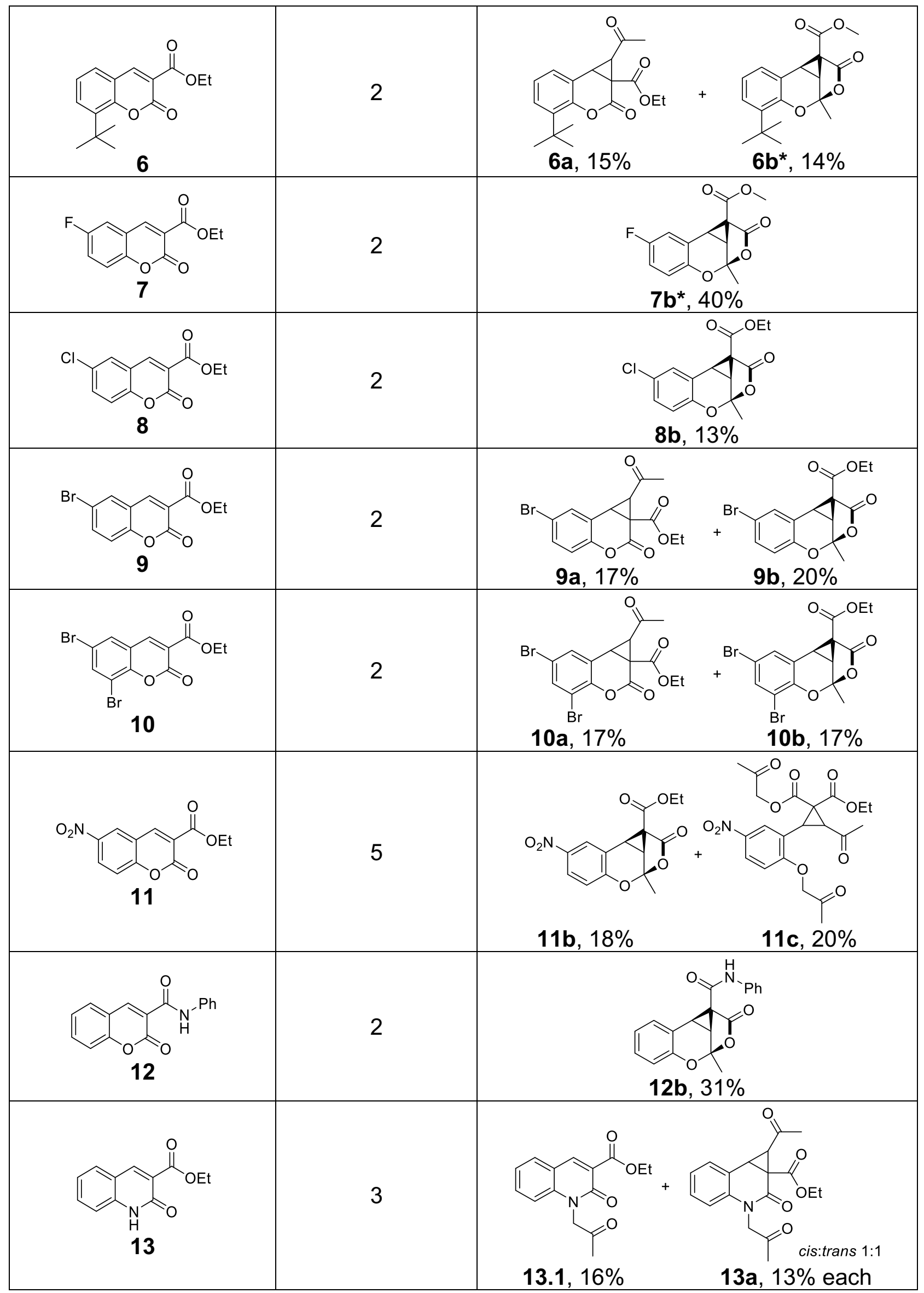




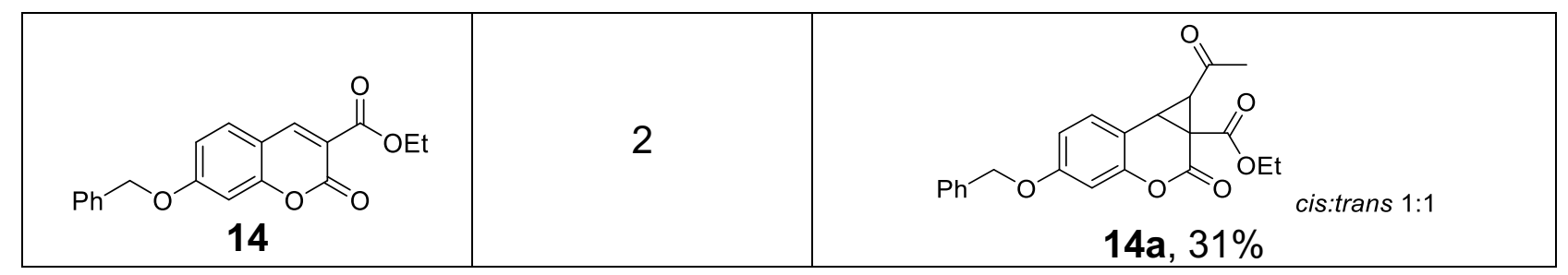

*Methyl ester of the product was observed when the reaction mixture was washed with methanol.

The structures of the 4,6-dibromo cyclopropylated coumarin 10a, 4,6-dibromo tricyclic ketal 10b, and cis and trans 6-methoxy cyclopropylated coumarins 5a and 5a' were confirmed using X-ray crystallography (Figure 3). The crystal structure for 10a showed twinned (more than one crystal) structure. Initial attempts to solve the crystal structure without accounting for the twin lead to flat anisotropic displacement parameters (ADPs). After further analysis, it was found that the data contained a smaller twin component that resulted in significant overlap with the larger twin component. This overlap complicates the integration of the reflections and is likely the main culprit in the large ADP ratios. The dataset was reprocessed as a twin to improve Rint data statistics. Only the data associated with the primary/larger component was used for structural analysis. Merge outliers were rejected upon creation of the HKL5 files. While twin refinement improved ADP behavior, several ADP associated irregularities (high max/min ADP ratios) remain. 


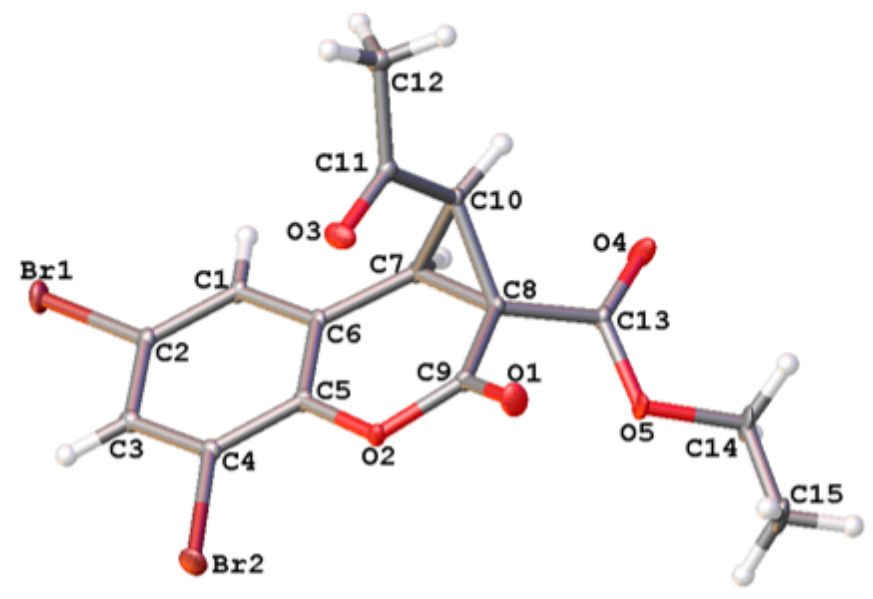

A

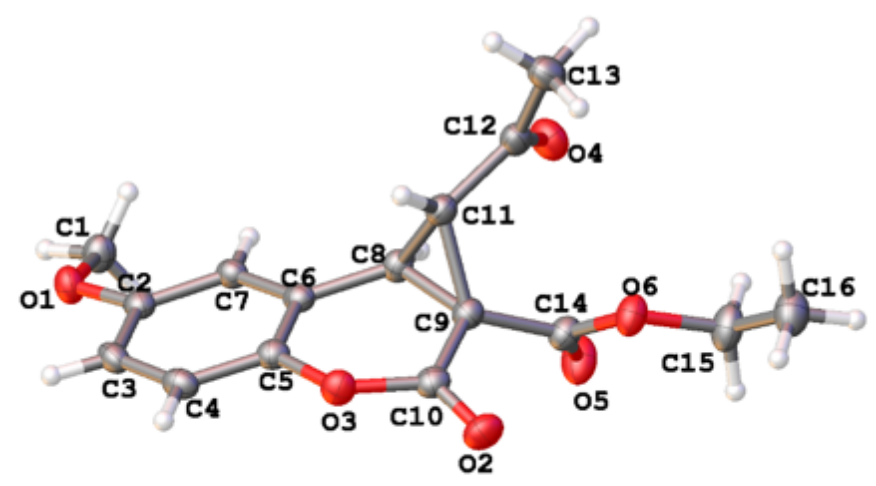

C

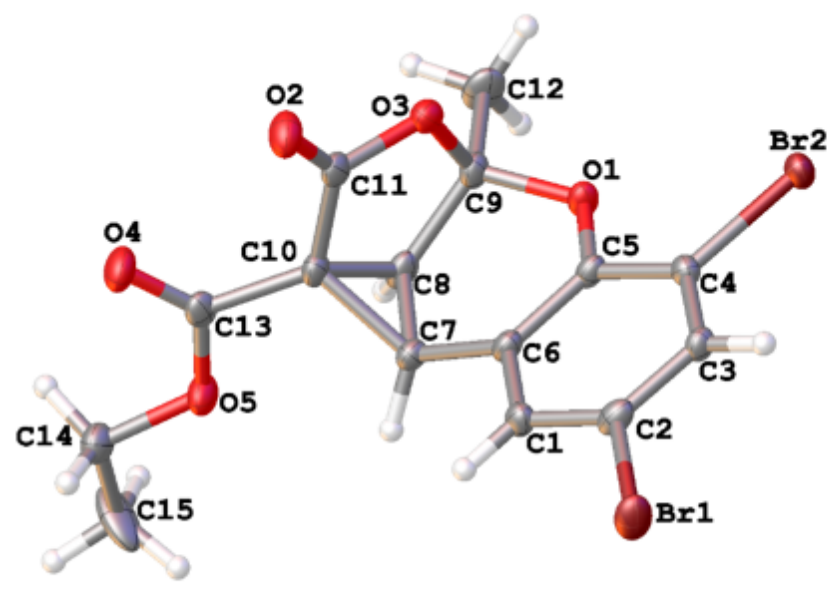

B

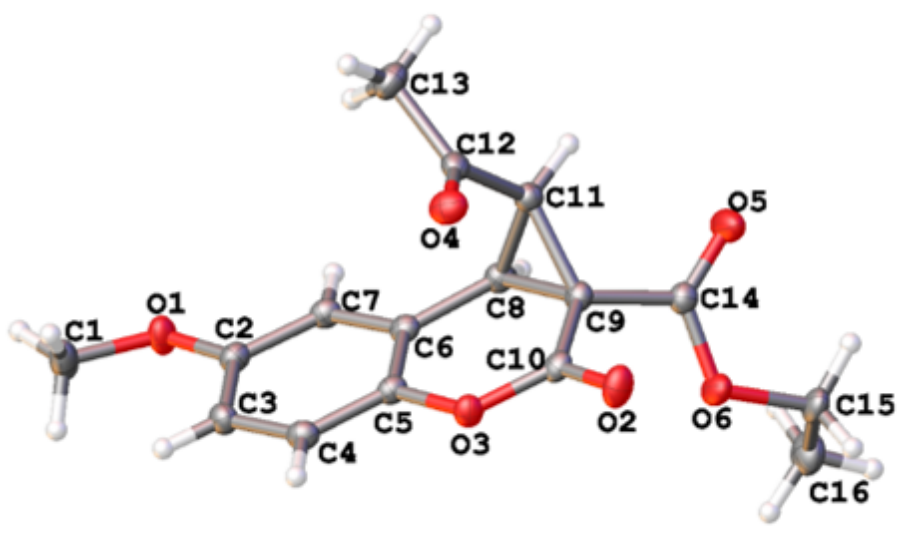

D

Figure 3. Crystal structures of cyclopropanated (A) dibromo coumarin ketone 10a, (B) dibromo coumarin lactone 10b, (C) cis 6-methoxy coumarin ketone 5a and (D) trans 6-methoxy coumarin ketone 5a' derivatives

In most of the cases, formation of the trans cyclopropylated product along with isomerized tricyclic ketal derivatives were observed, however, in the case of 6-methoxy, both cis and trans ketones were isolated, leading us to postulate that cis ketones undergo intermolecular rearrangement resulting in the formation of the lactone derivative by a potential mechanism delineated in Figure 3. 

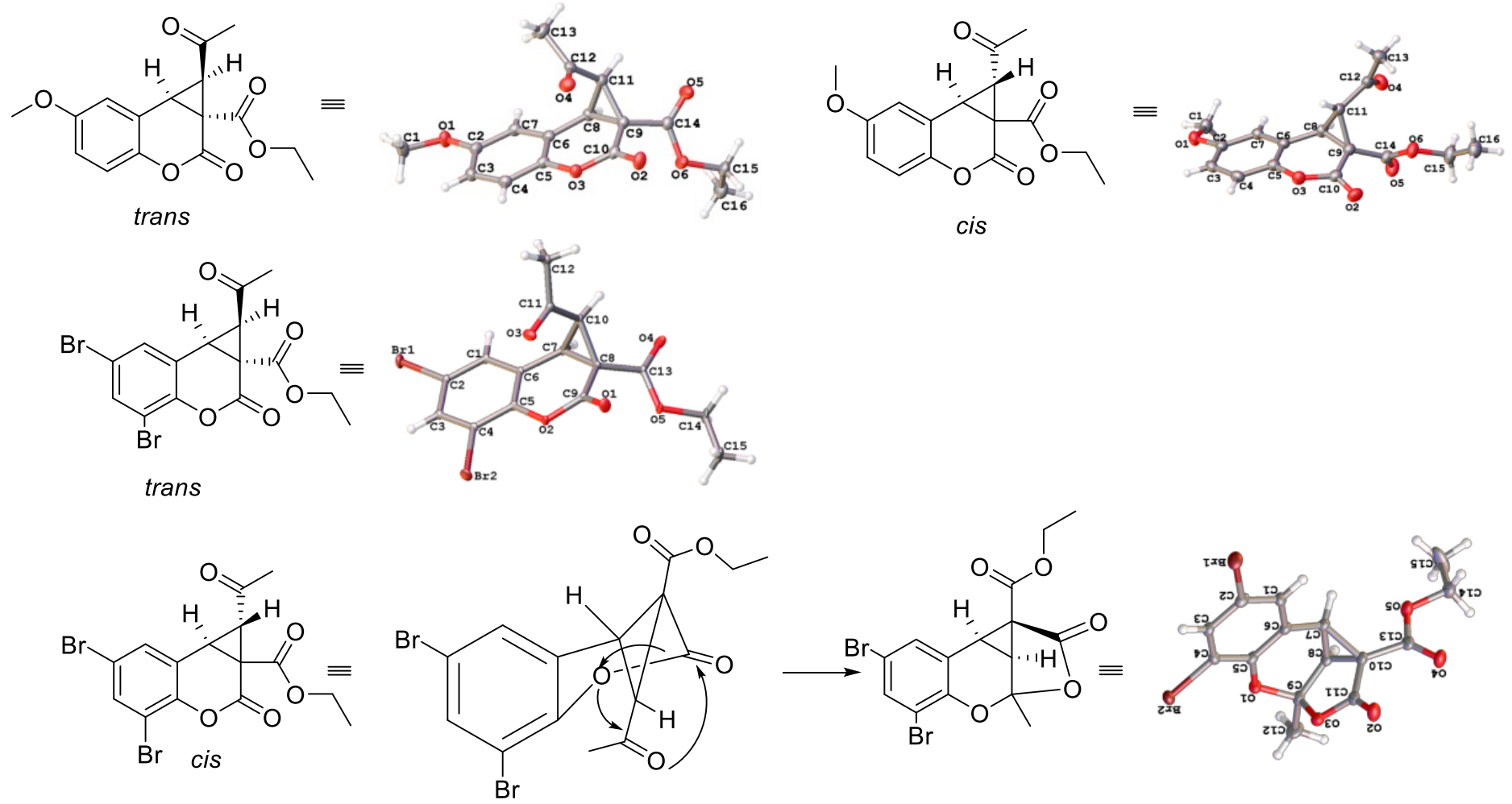

Figure 3: Possible mechanism for the formation of tricyclic ketals from the cyclopropyl caboxylate cis isomer.

To understand the potential antineoplastic effects of these scaffolds, representative compounds were tested for cytotoxicity in the triple negative breast cancer cell line MDA-MB-468 using an MTS assay (Figure 4). None of the compounds tested showed potent inhibition of cell proliferation at either 50 or $100 \mu \mathrm{M}$ with the exception of 5-diethylamide $15 \mathrm{a}$ which was determined to possess an $\mathrm{IC}_{50}=21$ $\mu \mathrm{M}$. 


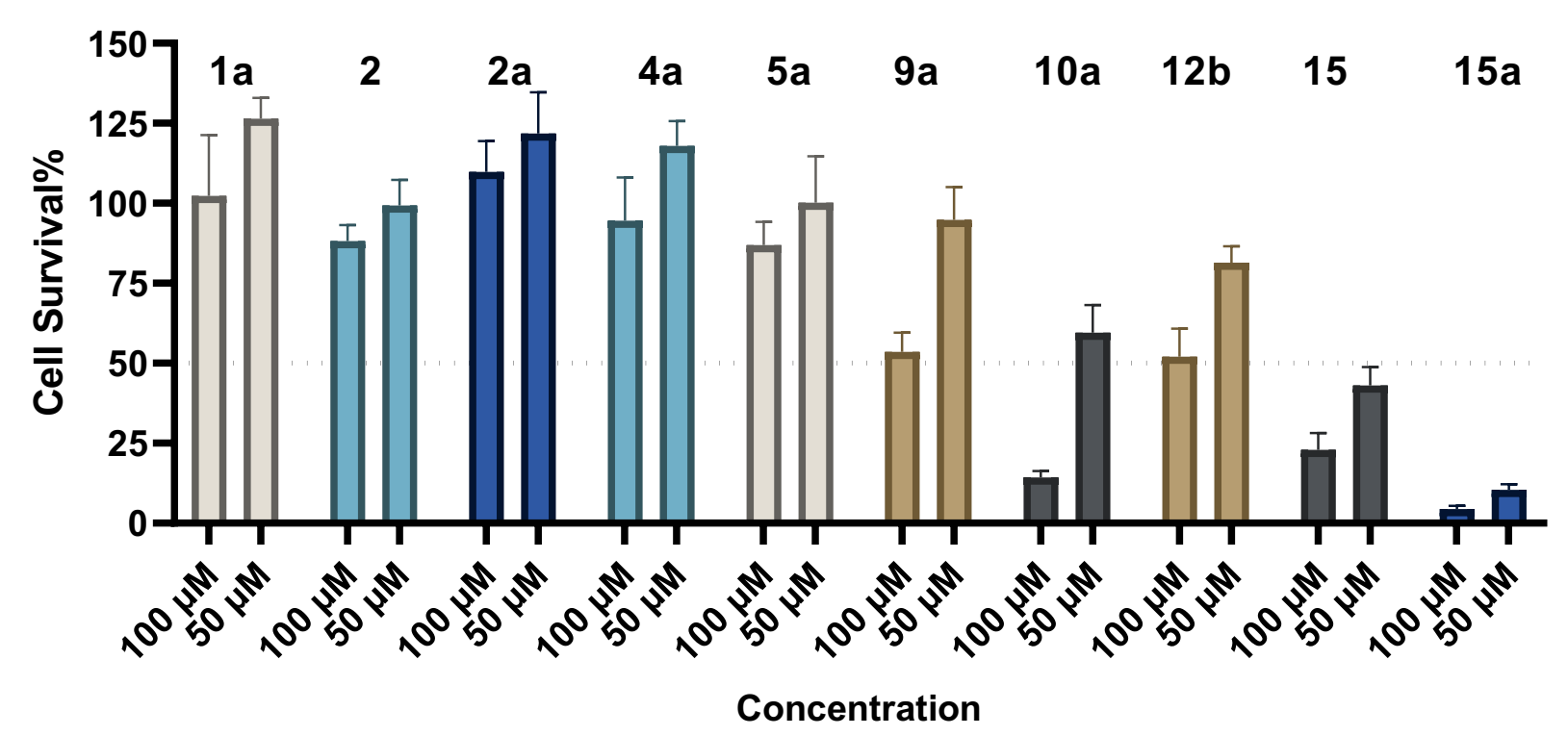

Figure 4. Effect of selected compounds at 100 and $50 \mu \mathrm{M}$ on cell survival of MDA-MB-468 triple negative breast cancer cells after 72 -hour treatment. Values are mean of $n=4$ experiments $\pm S$.D.

In conclusion, we have identified a synthetically simple, single step route for the synthesis of previously unreported highly strained tricyclic ketals based around the bioactive coumarin ring structure. Substrate scope at the 4-position tolerates both electron withdrawing and donating groups, at the 6-position alkyl electron donating and withdrawing groups are tolerated. However, 6-methoxy does not form the tricyclic ketals. Similarly, substitution at the 5-position and full saturation fails to afford the tricyclic ketal product. We propose a plausible mechanism of formation involving intermolecular rearrangement of the cyclopropyl cis ketone. While the products are formed in low to moderate (10$40 \%$ ) yield, the single step is synthetically advantageous when compared to the multistep route likely needed to access these types of complex structures. While the tricyclic ketals are not highly active antineoplastic agents, they do possess some effect suggesting that further derivatization may afford more active compounds.

\section{Associated Content}


Experimental procedures, characterization data, X-ray crystal data, NMR spectra (PDF).

\section{AUTHOR INFORMATION}

Corresponding author: Paul Trippier, ORCID ID: 0000-0002-4947-5782

\section{ACKNOWLEDGEMENTS}

This project was supported by the National Cancer Institute of the National Institute of Health under award number R01 CA226436 (PCT).

\section{CONFLICT OF INTEREST STATEMENT}

The authors declare no conflicts of interest. 


\section{REFERENCES}

1. Lovering, F.; Bikker, J.; Humblet, C., Escape from flatland: increasing saturation as an approach to improving clinical success. J Med Chem 2009, 52 (21), 6752-6.

2. Wei, W.; Cherukupalli, S.; Jing, L.; Liu, X.; Zhan, P., Fsp(3): A new parameter for drug-likeness. Drug Discov Today 2020.

3. Meyers, J.; Carter, M.; Mok, N. Y.; Brown, N., On the origins of three-dimensionality in drug-like molecules. Future Med Chem 2016, 8 (14), 1753-67.

4. Zhou, J.; Campbell-Conroy, E. L.; Silina, A.; Uy, J.; Pierre, F.; Hurley, D. J.; Hilgraf, N.; Frieman, B. A.; DeNinno, M. P., Synthesis of fused bicyclic piperidines: potential bioactive templates for medicinal chemistry. J Org Chem 2015, 80 (1), 70-9.

5. Cox, B.; Duffy, J.; Zdorichenko, V.; Bellanger, C.; Hurcum, J.; Laleu, B.; Booker-Milburn, K. I.; Elliott, L. D.; Robertson-Ralph, M.; Swain, C. J.; Bishop, S. J.; Hallyburton, I.; Anderson, M., Escaping from Flatland: Antimalarial Activity of sp(3)-Rich Bridged Pyrrolidine Derivatives. ACS Med Chem Lett 2020, 11 (12), 2497-2503.

6. Zheng, Y.; Tice, C. M.; Singh, S. B., The use of spirocyclic scaffolds in drug discovery. Bioorg Med Chem Lett 2014, 24 (16), 3673-82.

7. Talele, T. T., The "Cyclopropyl Fragment" is a Versatile Player that Frequently Appears in Preclinical/Clinical Drug Molecules. J Med Chem 2016, 59 (19), 8712-8756.

8. $\quad$ Kupeli Akkol, E.; Genc, Y.; Karpuz, B.; Sobarzo-Sanchez, E.; Capasso, R., Coumarins and Coumarin-Related Compounds in Pharmacotherapy of Cancer. Cancers (Basel) 2020, 12 (7).

9. Zang, T.; Verma, K.; Chen, M.; Jin, Y.; Trippier, P. C.; Penning, T. M., Screening baccharin analogs as selective inhibitors against type 5 17beta-hydroxysteroid dehydrogenase (AKR1C3). Chem Biol Interact 2015, 234, 339-48.

10. Verma, K.; Zang, T.; Gupta, N.; Penning, T. M.; Trippier, P. C., Selective AKR1C3 Inhibitors Potentiate Chemotherapeutic Activity in Multiple Acute Myeloid Leukemia (AML) Cell Lines. ACS Med Chem Lett 2016, 7 (8), $774-9$.

11. Verma, K.; Gupta, N.; Zang, T.; Wangtrakluldee, P.; Srivastava, S. K.; Penning, T. M.; Trippier, P. C., AKR1C3 Inhibitor KV-37 Exhibits Antineoplastic Effects and Potentiates Enzalutamide in Combination Therapy in Prostate Adenocarcinoma Cells. Mol Cancer Ther 2018, 17 (9), 1833-1845.

12. Verma, K.; Zang, T.; Penning, T. M.; Trippier, P. C., Potent and Highly Selective Aldo-Keto Reductase 1C3 (AKR1C3) Inhibitors Act as Chemotherapeutic Potentiators in Acute Myeloid Leukemia and T-Cell Acute Lymphoblastic Leukemia. J Med Chem 2019, 62 (7), 3590-3616.

13. Morsy, A.; Trippier, P. C., Reversal of Apalutamide and Darolutamide Aldo-Keto Reductase 1C3-Mediated Resistance by a Small Molecule Inhibitor. ACS Chem Biol 2020, 15 (3), 646-650.

14. Little, R. D.; Dawson, J. R., MIRC (Michael Initiated Ring Closure) Reactions Formation of Three, Five, Six and Seven Membered Rings. Tetrahedron Lett. 1980, 21 (27), 2609-2612.

15. Das, I.; Pal, T. K.; Pathak, T., Diastereoselective michael initiated ring closure on vinyl sulfone-modified carbohydrates: a stereospecific and general route to alpha-substituted cyclopropanes. J Org Chem 2007, 72 (24), $9181-9$.

16. Kozhushkov, S. I.; Leonov, A.; de Meijere, A., Simple Large-Scale Preparation of 1,2,3-Tris-Acceptor Substituted Cyclopropanes. Synthesis 2003, 06, 2003.

17. Xin, X.; Zhang, Q.; Liang, Y.; Zhang, R.; Dong, D., Tandem halogenation/Michael-initiated ring-closing reaction of alpha, beta-unsaturated nitriles and activated methylene compounds: one-pot diastereoselective synthesis of functionalized cyclopropanes. Org Biomol Chem 2014, 12 (15), 2427-35.

18. Yuan, W. C.; Lei, C. W.; Zhao, J. Q.; Wang, Z. H.; You, Y., Organocatalytic Asymmetric Cyclopropanation of 3Acylcoumarins with 3-Halooxindoles: Access to Spirooxindole-cyclopropa[c]coumarin Compounds. J Org Chem 2021, 86 (3), 2534-2544.

19. Slates, H. L.; Weber, S.; Wendler, N. L., Reactions of chloroacetone in basic media. J. Org. Chem. 1969, 34 (2), 457-459.

20. Sun, J. C.; Wang, X. H.; Ji, C. B.; Peng, Y. Y.; Zeng, X. P., Enantioselective Construction of Chiral Cyclopropa[c]coumarins via Lewis Base-Catalyzed Cyclopropanation. J Org Chem 2020, 85 (23), 14963-14970.

21. Guo, J.; Liu, Y.; Li, X.; Liu, X.; Lin, L.; Feng, X., Nickel(ii)-catalyzed enantioselective cyclopropanation of 3alkenyl-oxindoles with phenyliodonium ylide via free carbene. Chem Sci 2016, 7 (4), 2717-2721.

22. Antoniotti, S.; Genin, E.; Michelet, V.; Genet, J. P., Highly efficient access to strained bicyclic ketals via goldcatalyzed cycloisomerization of bis-homopropargylic diols. J Am Chem Soc 2005, 127 (28), 9976-7. 
23. Traven, V. F.; Tolmachev, A. Y.; Podhaluzina, N. Y.; Kanevskii, D. S.; Solovieva, N. P., New ways of lactone ring shortening and cylcopropanation in coumarin derivatives. Heterocycl. Commun. 1999, 5, 69-76.

24. A., B.; Trendafilova, A.; Ivanov, C.; Rodios, N. A., Cyclopropanation reaction of 3-Acyl-2H-1-benzopyran-2-ones with phenacylbromide in phase transfer systems. Tetrahedron 1993, 49, 2275-2286.

25. Shoemaker, R. H., The NCl60 human tumour cell line anticancer drug screen. Nat Rev Cancer 2006, 6 (10), $813-$

23. 


\section{Table of Contents Graphic}

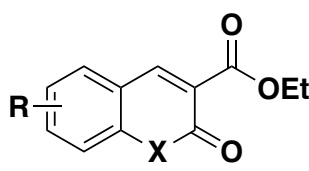

$\mathrm{X}=\mathrm{O}$ or $\mathrm{NH}$

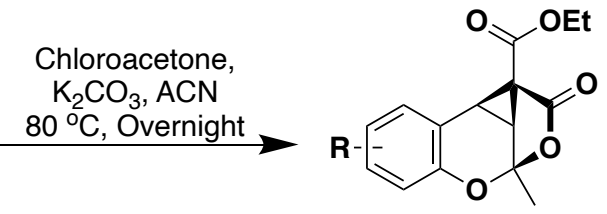

9 Examples

Sole Product with

$\mathrm{R}=4-\mathrm{CH}_{3}$, 4-F, 4-Cl, 4-NO

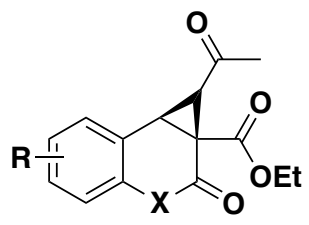

10 Examples

$\mathrm{X}=\mathrm{O}$ or $\mathrm{NH}$

Sole Product with

R = 5-Substitution, $\mathrm{H}$, 4-OMe

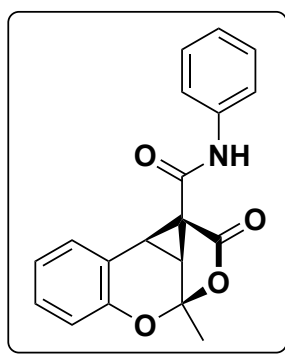

Sole Product from Appropriatly Substituted Coumarin 